\title{
Tracking the performance, energetics and biomechanics of international versus national level swimmers during a competitive season
}

\author{
Mário J. Costa $\cdot$ José A. Bragada $\cdot$ Jean E. Mejias • \\ Hugo Louro • Daniel A. Marinho • António J. Silva • \\ Tiago M. Barbosa
}

Received: 15 December 2010/Accepted: 31 May 2011/Published online: 15 June 2011

(C) Springer-Verlag 2011

\begin{abstract}
The purpose of this study was to track and compare the changes of performance, energetic and biomechanical profiles of international (Int) and national (Nat) level swimmers during a season. Ten Portuguese male swimmers (four Int and six Nat level subjects) were evaluated on three different time periods $\left(\mathrm{TP}_{1}, \mathrm{TP}_{2}, \mathrm{TP}_{3}\right)$ of the 2009-2010 season. Swimming performance was assessed based on official time's lists of the 200-m freestyle event. An incremental set of $7 \times 200 \mathrm{~m}$ swims was applied to assess the energetic and biomechanical data. Measurements were made of: (1) velocity at the $4 \mathrm{mmol}$ of lactate levels (V4), stroke index at V4 (SI@V4) and propelling efficiency at $V 4\left(\eta_{\mathrm{p}} @ V 4\right)$, as energetic estimators; (2) stroke length at V4 (SL@V4) and stroke frequency at V4 (SF@V4), as biomechanical variables. The results demonstrated no significant variations in all variables throughout the season.
\end{abstract}

Communicated by Jean-René Lacour.

M. J. Costa $(\bowtie)$ · J. A. Bragada · J. E. Mejias · T. M. Barbosa Sport Sciences Department, Polytechnic Institute of Bragança, Campus Sta. Apolónia, Ap. 1101-75, 5300 Bragança, Portugal

e-mail: mario.costa@ipb.pt

M. J. Costa $\cdot$ A. J. Silva

University of Trás-os-Montes and Alto Douro,

Vila Real, Portugal

D. A. Marinho

University of Beira Interior, Covilhã, Portugal

H. Louro

Sport Sciences School of Rio Maior, Rio Maior, Portugal

M. J. Costa - J. A. Bragada - J. E. Mejias - H. Louro ·

D. A. Marinho - A. J. Silva - T. M. Barbosa

Research Center in Sports Science, Health and Human

Development, Vila Real, Portugal
The inter-group comparison pointed out higher values for Int swimmers, with statistical differences for the $200 \mathrm{~m}$ performance in all time periods. Near values of the statistical significance were demonstrated for the SI@V4 in $\mathrm{TP}_{1}$ and $\mathrm{TP}_{3}$. The tracking based on $K$ values was high only for the SI@V4. It is concluded that a high stability can be observed for elite swimmers performance, energetic and biomechanical profiles throughout a single season. Int swimmers are able to maintain a higher energetic and biomechanical capacity than Nat ones at all times. The SI@V4 may be used as an indicator of performance variation.

Keywords Performance - Elite swimmers - Biophysics profile $\cdot$ Tracking $\cdot$ Freestyle

\section{Introduction}

The identification of the variables that can predict the swimming performance is one of the main topics in swimming science. Special emphasis has been given to the physiological/energetics and biomechanical assessment as determinant domains to achieve high levels of swimming performance (e.g. Barbosa et al. 2008).

At the moment, few papers investigated longitudinal data concerning the changes in energetics and/or biomechanical variables. However, most of them focused their attention in a single domain (energetics or biomechanical one). According to the literature, significant improvements in maximal oxygen consumption (Magel et al. 1975; Houston et al. 1981; Termin and Pendergast 2000), velocity at $4 \mathrm{mmol} \mathrm{L}^{-1}$ of lactate levels (Reis and Alves 2006; Robertson et al. 2010) and lactate tolerance (Sharp et al. 1984; Pyne et al. 2001) were observed due to the 
training process. Changes in the biomechanical variables were observed as well. Throughout full training seasons, significant improvements were reported for the stroke length (SL) (Hay and Guimarães 1983), stroke frequency (SF) (Huot-Marchand et al. 2005) and no significant changes were found for both SL and SF (Mingheli and Castro 2006). Few other studies investigated at the same time both domains (Wakayoshi et al. 1993; Termin and Pendergast 2000; Anderson et al. 2008; Latt et al. 2009a, $2009 b)$. Decreases in blood lactate concentrations related to swimming velocity were observed after 6 months of aerobic training (Wakayoshi et al. 1993). A training program based on the stroke frequency-velocity relationship can improve the swimmer's biomechanical and energetic profile enhancing the swimming performance (Termin and Pendergast 2000). When monitoring changes in test measures for $3.6 \pm 2.5$ years, the stroke frequency at $4 \mathrm{mmol} \mathrm{L}{ }^{-1}$ of blood lactate concentration (SF@V4) for males $(r=0.41)$ and the skinfolds for females $(r=$ $-0.53)$, showed to be reliable variables to predict the Breaststroke performance (Anderson et al. 2008). For two consecutive seasons, it was reported that the stroke index (SI) best correlates to the $400-\mathrm{m}$ freestyle performance for both young male and female swimmers (Latt et al. 2009a, b).

Moreover, it is known that swimmers from different competitive levels present different energetic and biomechanical profiles. Several cross-sectional studies have already compared different cohort groups. High-level swimmers are more economical (energy cost at a given velocity) and efficient than lower level ones (Toussaint 1990; Fernandes et al. 2006). Moreover, the SL (Seifert et al. 2007) and the propelling efficiency $\left(\eta_{\mathrm{p}}\right)$ (Toussaint 1990) are higher in elite swimmers, while the active drag (Pendergast et al. 2006) is lower than other competitive levels. International swimmers present higher SI values when compared to the nationals (Sánchez and Arellano 2002).

To the best of our knowledge, no study until now tried to deal with the question if the same type of training load induces different responses according to the swimmers competitive level during a full competitive season. Therefore, the aim of this research was to: (1) track the stability and the changes of performance, energetic and biomechanical profiles from international and national level swimmers during a full competitive season; (2) compare the performance, energetic and biomechanical profiles between both cohort groups. It was hypothesized that (1) there was a performance enhancement throughout the competitive season, along with a high stability in energetic and biomechanical variables and; (2) there are different energetic and biomechanical profiles comparing international versus national level swimmers.

\section{Methods}

Subjects

Ten Portuguese male swimmers of international (Int) and national (Nat) level, volunteered to serve as subjects. It was considered that Int level swimmers are the ones $(N=4$; $20 \pm 3.40$ years old; $1.83 \pm 0.08 \mathrm{~m}$ of height; $73.15 \pm$ $10.13 \mathrm{~kg}$ of body mass; $21.76 \pm 1.53 \mathrm{~kg} . \mathrm{m}^{-2}$ of body mass index; $1.90 \pm 0.09 \mathrm{~m}$ of arm span and; $112.39 \pm$ $4.22 \mathrm{~s}$ of personal record in the $200 \mathrm{~m}$ freestyle event) with regular participation on international meetings in the previous season, representing the Portuguese National Swimming Team. It was defined that Nat level swimmers are $(N=6 ; 20 \pm 3.25$ years old; $1.77 \pm 0.05 \mathrm{~m}$ of height; $72.93 \pm 6.34 \mathrm{~kg}$ of body mass; $23.19 \pm 1.80 \mathrm{~kg} . \mathrm{m}^{-2}$ of body mass index; $1.85 \pm 0.04 \mathrm{~m}$ of arm span and; $118.43 \pm 2.21 \mathrm{~s}$ of personal record in the 200-m freestyle event) the ones with regular presence in the national championships.

Study design

The swimmers were studied in three occasions during the 2009-2010 calendar: (1) December 2009 (TP 1 ); (2) March $2010\left(\mathrm{TP}_{2}\right)$ and; (3) June $2010\left(\mathrm{TP}_{3}\right)$. The $\mathrm{TP}_{1}, \mathrm{TP}_{2}$ and $\mathrm{TP}_{3}$ coincided with the participation in the Winter Short Course National Championships, Winter Long Course National Championships and Summer National Championships, respectively. In the time period between tests the swimmers completed a full training preparation. Swim training generally consisted of a mixture of low, moderate and intense training characterized by: (1) training units $(\mathrm{tu})\left(\mathrm{TP}_{1}\right.$ : $8.88 \pm 0.64$ tu week ${ }^{-1} ; \mathrm{TP}_{2}: 9.00 \pm 0.85$ tu week $^{-1}$ TP $_{3}$ : $8.73 \pm 0.90$ tu week $\left.^{-1}\right)$; (2) volume $\left(\mathrm{TP}_{1}: 44.53 . \pm 6.45\right.$ km week ${ }^{-1} ; \mathrm{TP}_{2}: 43.87 \pm 5.86 \mathrm{~km} \mathrm{week}^{-1} ; \mathrm{TP}_{3}: 43.61 \pm$ $8.25 \mathrm{~km}$ week $\left.^{-1}\right)$; (3) low aerobic tasks $\left(\mathrm{TP}_{1}\right.$ : $39.06 . \pm$ $3.11 \mathrm{~km}^{2}$ week $^{-1}$; $\mathrm{TP}_{2}: 38.41 \pm 2.82 \mathrm{~km} \mathrm{week}^{-1} ; \mathrm{TP}_{3}$ : $39.14 \pm 3.61 \mathrm{~km} \mathrm{week}^{-1}$ ); (4) intensity corresponding to their aerobic capacity $\left(\mathrm{TP}_{1}: 2.35 \pm 0.95 \mathrm{~km} \mathrm{week}{ }^{-1} ; \mathrm{TP}_{2}\right.$ : $2.16 \pm 0.96 \mathrm{~km} \mathrm{week}^{-1} ; \mathrm{TP}_{3}: 1.55 \pm 0.41 \mathrm{~km} \mathrm{week}^{-1}$ ); (5) intensity corresponding to their aerobic power $\left(\mathrm{TP}_{1}\right.$ : $1.41 \pm 0.38 \mathrm{~km} \mathrm{week}^{-1} ; \mathrm{TP}_{2}: 1.25 \pm 0.38 \mathrm{~km}$ week $^{-1}$; $\mathrm{TP}_{3}: 1.00 \pm 0.28 \mathrm{~km}$ week $^{-1}$ ); (6) lactate tolerance training $\left(\mathrm{TP}_{1}: 0.76 \pm 0.26 \mathrm{~km}\right.$ week ${ }^{-1} ; \mathrm{TP}_{2}: 0.80 \pm 0.18 \mathrm{~km}$ week $^{-1} ; \mathrm{TP}_{3}$ : $0.89 \pm 0.15 \mathrm{~km} \mathrm{week}^{-1}$ ); (7) intensity of maximal lactate power $\left(\mathrm{TP}_{1}: 0.27 \pm 0.05 \mathrm{~km}^{2}\right.$ week $^{-1}$; $\mathrm{TP}_{2}: \quad 0.29 \pm 0.08 \mathrm{~km}$ week ${ }^{-1} ; \quad \mathrm{TP}_{3}: \quad 0.50 \pm 0.35 \mathrm{~km}$ week $\left.^{-1}\right)$ and; (8) velocity training $\left(\mathrm{TP}_{1}: 0.68 \pm 0.22 \mathrm{~km}\right.$ week $^{-1} ; \quad \mathrm{TP}_{2}: \quad 0.95 \pm 0.17 \mathrm{~km} \mathrm{week}^{-1} ; \quad \mathrm{TP}_{3}: 0.54 \pm$ $0.16 \mathrm{~km} \mathrm{week}^{-1}$ ). Technical training was performed during the low aerobic tasks, including practicing technical drills. 
On each occasion the swimmers completed an intermittent set of $7 \times 200 \mathrm{~m}$ front crawl with increasing velocity as described elsewhere (e.g. Barbosa et al. 2008). The velocities and increments were chosen, so that swimmers would attain their best performance on the last trial. The starting velocity was set at a speed, which represented a low training pace, approximately $0.3 \mathrm{~m} \mathrm{~s}^{-1}$ less than the swimmer's best performance. After each successive 200-m swim, the velocity was increased by $0.05 \mathrm{~m} \mathrm{~s}^{-1}$ until exhaustion and/or until the swimmer could no longer swim at the predetermined pace. A 30-s resting period was used between trials to collect blood samples. Underwater pacemaker lights (GBK-Pacer, GBK Electronics, Aveiro, Portugal), on the bottom of a 50-m swimming pool, were used to control the swimming velocity and to help the swimmers keep an even pace along each lap and step. In addition, elapsed time for each trial was measured with a chronometer to control the swimmer's velocity.

Performance data collection

Swimming performance was assessed based on times lists of the 200-m freestyle event during official long course competitions from local, regional, national and/or international level. The time gap between energetic plus biomechanical assessment and swimming performance was made in less than 2 weeks.

\section{Energetics data collection}

Energetics assessment included the analysis of the velocity at $4 \mathrm{mmol} \mathrm{L}^{-1}$ of blood lactate concentration (V4) as an aerobic capacity indicator, the stroke index and the propelling efficiency at the same velocity (SI@V4 and $\eta_{\mathrm{p}} @ V 4$, respectively) as swim efficiency estimators. To determine the $V 4$, capillary blood samples were collected from the ear lobe to determine the lactate concentrations $\left[\mathrm{La}^{-}\right]$with an auto-analyzer (YSI 1500 L, Yellow Springs, OH, USA). Collecting process occurred during the $30-\mathrm{s}$ resting period between trials of the intermittent protocol. The auto-analyzer calibration was initially performed with several standard lactate solutions $\left(2,4,8\right.$ and $\left.16 \mathrm{mmol} \mathrm{L}^{-1}\right)$. The $\left[\mathrm{La}^{-}\right]$values allowed the individual $V 4$ measurement interpolating the average lactate value $\left(4 \mathrm{mmol} \mathrm{L}^{-1}\right)$, with the exponential curve of lactate/speed. The SI@V4, considered as one of the swimming stroke efficiency indexes, was adapted and computed as (Costill et al. 1985):

SI@V4=V4 × SL@V4

where SI@V4 is the stroke index at $V 4\left(\mathrm{~m}^{2} \mathrm{c}^{-1} \mathrm{~s}^{-1}\right), V 4$ is the $4 \mathrm{mmol} \mathrm{L}^{-1}$ lactate concentration velocity $\left(\mathrm{m} \mathrm{s}^{-1}\right)$ and the SL@V4 is the stroke length at V4 (m). The $\eta_{p} @ V 4$ was also estimated as being (Zamparo et al. 2005): $\eta_{p} @ V 4=\left(\frac{V 4 \times 0.9}{2 \pi \times \mathrm{SF} @ V 4 \times l}\right) \cdot \frac{2}{\pi}$

where $V 4$ is the $4 \mathrm{mmol} \mathrm{L}^{-1}$ lactate concentration velocity $\left(\mathrm{m} \mathrm{s}^{-1}\right)$, the SF@V4 is the stroke frequency at $V 4(\mathrm{~Hz})$ and 1 is the arm's length (m). The 1 is computed trigonometrically measuring the arm's length and considering the average elbow angles during the insweep of the arm pull as reported by Zamparo (2006). Equation 2 is properly speaking the Froude efficiency. The difference between Froude and propelling efficiency is that the first one does not take into account the effect of the internal mechanical work to total mechanical work production. As reported by Zamparo et al. (2005), at the range of swim velocity verified in these swimmers, internal mechanical work is rather low and can be neglected. So, propelling efficiency becomes very similar to Froude efficiency.

Biomechanical data collection

For biomechanical assessment both stroke frequency at $V 4$ and stroke length at V4 (SF@V4 and SL@V4, respectively) were measured. $S F$ was obtained with a crono-frequency meter (Golfinho Sports MC 815, Aveiro, Portugal) from three consecutive stroke cycles, in the middle of each lap during each trial. Then, $S F$ values were converted to International System Units (Hz). The SF@V4 was calculated by the interpolation of the $S F$ value in the $V 4$ by the curve $S F$-velocity. SL@V4 was estimated as being (Craig et al. 1985):

$\mathrm{SL} @ V 4=\frac{V 4}{\mathrm{SF} @ V 4}$

where SL@V4 is the stroke length at $V 4(\mathrm{~m}), V 4$ is the $4 \mathrm{mmol} \mathrm{L}{ }^{-1}$ lactate concentration velocity $\left(\mathrm{m} \mathrm{s}^{-1}\right)$, and the SF@V4 is the stroke frequency at V4 (Hz).

\section{Statistical procedures}

Normality was determined by Shapiro-Wilk test. Since, the very low value of the $N$ (i.e., $N<30$ ) and the rejection of the null hypothesis $\left(H_{0}\right)$ in the normality assessment, nonparametric procedures were adopted. Longitudinal assessment was made based on two approaches: (1) mean stability and; (2) normative stability. For mean stability, mean plus one standard deviation and quartiles were computed for each time period. Data variation was analyzed with Friedman test, as well the Wilcoxon signed-rank test to assess differences between time periods $\left(\mathrm{TP}_{1}\right.$ vs. $\mathrm{TP}_{2} ; \mathrm{TP}_{1}$ vs. $\mathrm{TP}_{3} ; \mathrm{TP}_{2}$ vs. $\mathrm{TP}_{3}$ ). The differences in both cohort groups (Int vs. Nat level) were analyzed computing the Mann-Whitney $U$ test. Normative stability was analyzed with the Cohen's Kappa $(K)$ plus one standard deviation, 
with a confidence interval of $95 \%$ as proposed by Costa et al. (2010a). The qualitative interpretation of $K$ values was made according to Landis and Koch (1977) suggestion, where the stability is: (1) excellent if $K \geq 0.75$; (2) moderate if $0.40 \leq K<0.75$ and; (3) low if $K<0.40$. The Ranking Spearman correlation coefficient was also computed as another normative stability parameter. Qualitatively, stability was considered to be: (1) high if $r \geq 0.60$; (2) moderate if $0.30 \leq r<0.60$ and; (3) low if $r<0.30$, adapted from Malina (2001). All statistical procedures were conducted with SPSS software (v. 13.0, Apache Software Foundation, Chicago, IL, USA). However, the $K$ value was computed with the Longitudinal Data Analysis software (v. 3.2, Dallas, USA). The level of statistical significance was set at $P \leq 0.05$.

\section{Results}

Figure 1 present the 200-m freestyle performance variation during the three consecutive time periods. No significant variations were verified throughout the season. Wilcoxon tests also demonstrated no significant differences between pair wise time periods. However, values with statistical significance were observed when comparing both cohort groups: $\mathrm{TP}_{1}(\mathrm{Int} 200 \mathrm{~m}=115.38 \pm 4.33 \mathrm{~s} ; \mathrm{Nac} 200 \mathrm{~m}=121.43 \pm$ $2.46 \mathrm{~s} ; \quad P=0.03), \quad \mathrm{TP}_{2} \quad(\operatorname{Int} 200 \mathrm{~m}=115.85 \pm 3.12 \mathrm{~s}$; Nac200 $\mathrm{m}=121.25 \pm 2.60 \mathrm{~s} ; \quad P=0.03)$ and $\mathrm{TP}_{3}$ (Int200 m $=115.18 \pm 3.16 \mathrm{~s} ; \quad \mathrm{Nac} 200 \mathrm{~m}=121.41 \pm$ $3.02 \mathrm{~s} ; P=0.02)$.

Figure 2 presents the energetic variables variation throughout the competitive season. No significant variations were observed between pair wise time periods. The only exception was the comparison of Nat SI@V4 between $\mathrm{TP}_{2}$ and $\mathrm{TP}_{3}$ (SI@V4 $4_{\mathrm{TP} 2}=3.78 \pm 0.26 \mathrm{~m}^{2} \mathrm{c}^{-1} \mathrm{~s}^{-1} ; \mathrm{SI} @ V 4_{\mathrm{TP} 3}=$ $\left.3.88 \pm 0.22 \mathrm{~m}^{2} \mathrm{c}^{-1} \mathrm{~s}^{-1} ; P=0.05\right)$. Very close to the statistical significance cut-off value adopted were also verified for Nat SI@V4 between the $\mathrm{TP}_{1}$ and $\mathrm{TP}_{2}\left(\mathrm{SI} @ V 4_{\mathrm{TP} 1}=\right.$ $3.75 \pm 0.29 \mathrm{~m}^{2} \mathrm{c}^{-1} \mathrm{~s}^{-1} ; \quad \mathrm{SI} @ V 4_{\mathrm{TP} 2}=3.78 \pm 0.26 \mathrm{~m}^{2}$ $\left.\mathrm{c}^{-1} \mathrm{~s}^{-1} ; P=0.06\right)$ and between $\mathrm{TP}_{1}$ and $\mathrm{TP}_{3}\left(\mathrm{SI} @ V 4_{\mathrm{TP} 1}=\right.$ $3.75 \pm 0.29 \mathrm{~m}^{2} \mathrm{c}^{-1} \mathrm{~s}^{-1} ; \quad \mathrm{SI} @ V 4_{\mathrm{TP} 3}=3.88 \pm 0.22 \mathrm{~m}^{2}$ $\left.\mathrm{c}^{-1} \mathrm{~s}^{-1} ; P=0.07\right)$. Significant differences were demonstrated for V4 when comparing both groups on $\mathrm{TP}_{2}$ $\left(\right.$ IntV4 $=1.48 \pm 0.03 \mathrm{~m} \mathrm{~s}^{-1} ; \quad \mathrm{NacV} 4=1.42 \pm 0.06 \mathrm{~m}$ $\left.\mathrm{s}^{-1} ; P=0.05\right)$. Remaining variables presented no significant values. However, once again, the SI@V4 on the $\mathrm{TP}_{1}$ (In$\mathrm{tSI} @ V 4=4.12 \pm \quad 0.26 \mathrm{~m}^{2} \mathrm{c}^{-1} \mathrm{~s}^{-1} ; \quad$ NacSI@V4 = $\left.3.75 \pm 0.29 \mathrm{~m}^{2} \mathrm{c}^{-1} \mathrm{~s}^{-1} ; P=0.06\right)$ and $\mathrm{TP}_{3}(\mathrm{IntSI} @ V 4=$ $4.22 \pm 0.21 \mathrm{~m}^{2} \mathrm{c}^{-1} \mathrm{~s}^{-1} ; \quad \mathrm{NacSI} @ V 4=3.88 \pm 0.22 \mathrm{~m}^{2}$ $\left.\mathrm{c}^{-1} \mathrm{~s}^{-1} ; P=0.07\right)$ was very close to the statistical significance cut-off value.

Figure 3 presents the biomechanical parameters variation. Both variables presented no significant variations across the season and between time periods. No significant differences were also found comparing Int with Nat level swimmers. However, two trends can be observed. Nat swimmers increased both biomechanical variables while Int ones decreased SF@V4 and increased SL@V4.

Table 1 presents the relative changes (i.e. \%) in performance, energetics and biomechanics throughout the season from $\mathrm{TP}_{1}$ to $\mathrm{TP}_{2}, \mathrm{TP}_{2}$ to $\mathrm{TP}_{3}$ and the overall time period. From the $\mathrm{TP}_{1}$ to $\mathrm{TP}_{2}$ the Int group presented decreases in the relative change for almost all variables. The only exception was the SF@V4 (1.05 $\pm 5.14 \%)$. On the other hand, the opposite trend was observed for Nat swimmers. From the $\mathrm{TP}_{2}$ to $\mathrm{TP}_{3}$ both cohort groups revealed increases in all variables. The SI@V4 presented the highest change during the overall season (IntSI@V4 = 2.70 $\pm 5.98 \%$; NatSI@V4=3.70 \pm 4.47\%).

The $K$ values for a $95 \%$ of confidence interval, which expresses the overall stability on competitive level tracks throughout the season, were rather low for the $V 4$ $(K=0.23 \pm 0.26)$ and SL@V4 $(K=0.39 \pm 0.26)$. Moderate values were verified for the 200-m event $(K=$ $0.49 \pm 0.26), \quad \mathrm{SF} @ V 4 \quad(K=0.54 \pm 0.26)$, and $\eta_{p} @ V 4$ $(K=0.60 \pm 0.26)$. Only the SI@V4 presented a high stability $(K=0.80 \pm 0.26)$.

Table 2 presents the Spearman correlation coefficient values for pair wise time periods throughout competitive season. Correlations were significant in almost all paired data $(P<0.01)$. The tracking values of $200 \mathrm{~m}$ freestyle performance revealed moderate-high stability $(0.56 \leq r \leq 0.88)$.
Fig. 1 Variation of the 200-m freestyle performance during the competitive season. *Significant difference between Int and Nat swimmers performances $\left(\mathrm{TP}_{1} P=0.03\right.$; $\mathrm{TP}_{2} P=0.03 ; \mathrm{TP}_{3}=0.02$ )
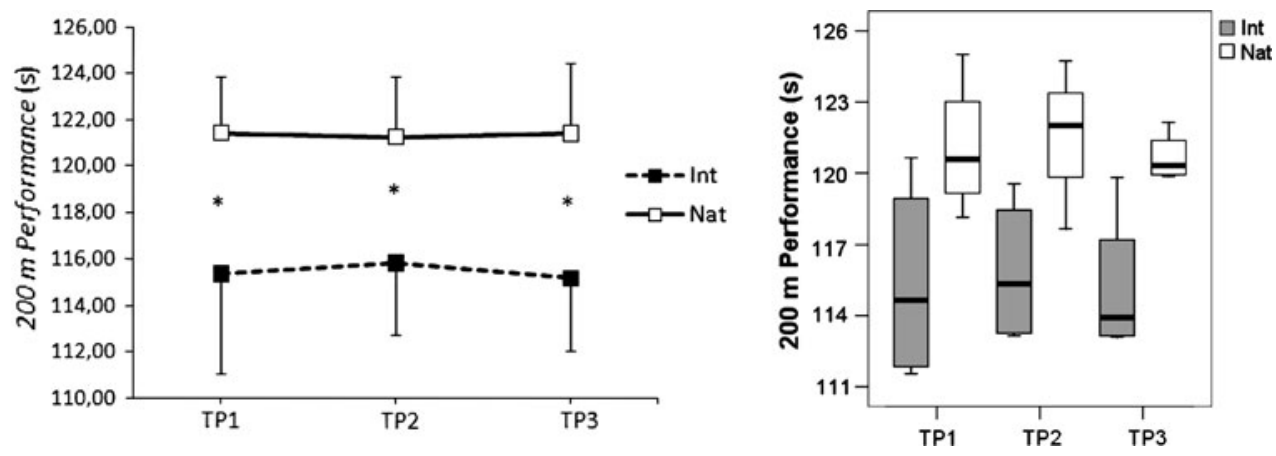
Fig. 2 Variation of energetic variables during the three time periods. *Significant difference from international and national level swimmers $V 4\left(\mathrm{TP}_{2}\right.$ $P=0.05) .{ }^{*}$ Significant differences in Nationals SI@V4 between $\mathrm{TP}_{2}$ and $\mathrm{TP}_{3}$ $(P=0.05)$
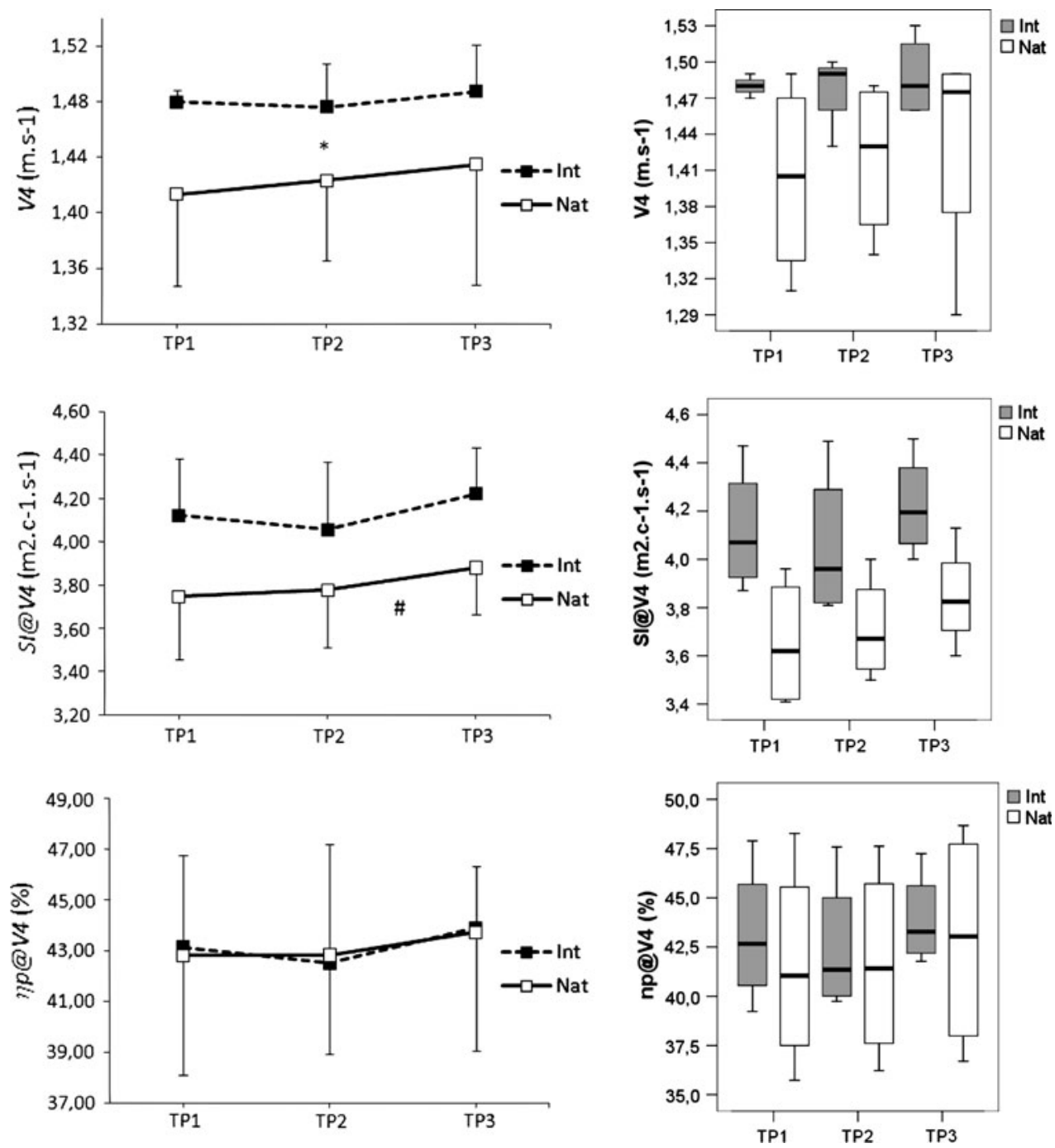

Both energetic and biomechanical values measured were also relatively high: SI@V4 (0.77 $\leq r \leq 0.95), \eta_{\mathrm{p}} @ V 4(0.76 \leq r$ $\leq 0.93)$,SF@V4 $(0.65 \leq r \leq 0.90)$, SL@V4 $\quad(0.65 \leq r$ $\leq 0.92$ ). The only exception was the $V 4$ with low-high stability $(0.33 \leq r \leq 0.82)$.

\section{Discussion}

The purpose of this study was to track the changes in performance, energetic and biomechanical variables and to longitudinally compare those variables between Int and Nat level swimmers submitted to the same training load. No significant differences in performance, energetic and biomechanical variables were observed for both Int and Nat swimmers across the season. For all variables, the stability in such reduced time frame was high. Int performances, energetic and biomechanical values were on a regular basis higher than Nat ones, giving to the SI@V4 the importance as an indicator of performance variation.
Performance

Despite slight changes, the 200-m freestyle performance remained unaltered over the course of the study. A lack of, or small magnitude of improvement, has been already published in a couple of papers (Costill et al. 1991; Pyne et al., 2001). Due to the maximal external load and technical ability reached, Nat and Int swimmers have some difficulties in promoting huge improvements in a single season. For some cases, swimmers from this competitive level are trained to improve a few decimal or centesimal seconds per season or during an Olympic cycle (Costa et al. 2010a). That is the reason why from a statistical point of view it becomes difficult to verify significant differences. However, a couple of papers presented significant improvements in performance after some weeks of training (Mujika et al. 2002) or even, from a season to another (e.g. Mujika et al. 1995; Termin and Pendergast 2000; Trinity et al. 2008).

The Int swimmers performance declines $(0.48 \pm 3.57 \%)$ from $\mathrm{TP}_{1}$ to $\mathrm{TP}_{2}$ and thereafter improves $(0.57 \pm 1.16 \%)$ 
Fig. 3 Variation of biomechanical parameters across the season
Table 1 Relative changes (\%) in performance, energetic and biomechanical variables between time periods and for the overall competitive season
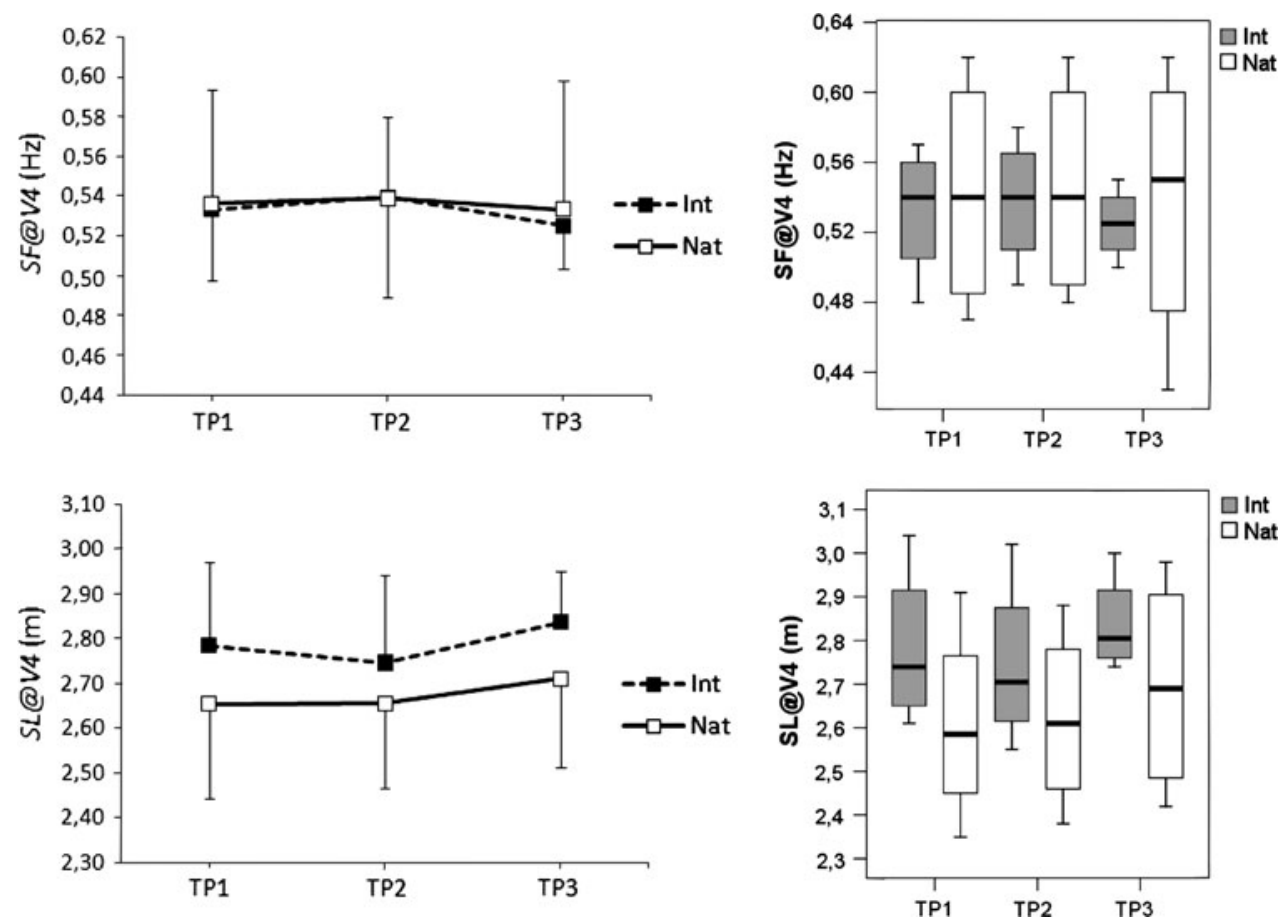

\begin{tabular}{llrrr}
\hline & & \multicolumn{2}{c}{ Between evaluation moments $(\%)$} & \multicolumn{2}{c}{ Overall season (\%) } \\
\cline { 3 - 4 } & & \multicolumn{1}{c}{$\mathrm{TP}_{1}-\mathrm{TP}_{2}$} & $\mathrm{TP}_{2}-\mathrm{TP}_{3}$ & \multicolumn{1}{c}{$\mathrm{TP}_{1}-\mathrm{TP}_{3}$} \\
\hline $200 \mathrm{~m}$ & Int & $-0.48 \pm 3.57$ & $0.57 \pm 1.16$ & $0.09 \pm 2.66$ \\
& Nat & $0.15 \pm 1.17$ & $-0.19 \pm 3.87$ & $-0.04 \pm 3.31$ \\
$V 4$ & Int & $-0.25 \pm 2.09$ & $0.83 \pm 4.41$ & $0.58 \pm 2.68$ \\
& Nat & $0.75 \pm 2.06$ & $0.77 \pm 3.08$ & $1.52 \pm 4.22$ \\
SI@V4 & Int & $-1.66 \pm 2.03$ & $4.36 \pm 6.35$ & $2.70 \pm 5.98$ \\
& Nat & $0.87 \pm 2.63$ & $2.83 \pm 2.59$ & $3.70 \pm 4.47$ \\
$\eta_{\mathrm{p}} @ V 4$ & Int & $-1.37 \pm 3.24$ & $3.52 \pm 5.10$ & $2.15 \pm 4.45$ \\
& Nat & $0.12 \pm 1.47$ & $2.17 \pm 5.26$ & $2.29 \pm 6.56$ \\
SF@V4 & Int & $1.05 \pm 5.14$ & $-2.83 \pm 7.21$ & $-1.71 \pm 4.49$ \\
& Nat & $0.59 \pm 2.45$ & $-1.59 \pm 8.30$ & $-1.00 \pm 10.11$ \\
SL@V4 & Int & $-1.37 \pm 3.24$ & $3.52 \pm 5.10$ & $2.15 \pm 4.45$ \\
& Nat & $0.12 \pm 1.47$ & $2.17 \pm 5.26$ & $2.29 \pm 6.56$ \\
\hline
\end{tabular}

from $\mathrm{TP}_{2}$ to $\mathrm{TP}_{3}$. Declines in sprint performance were also observed after 6 weeks of training with an increased volume in collegiate swimmers (Costill et al. 1991). Literature suggests that swimming efforts from $30 \mathrm{~s}$ to 4 min require the contribution from both aerobic and anaerobic systems (Troup 1991). Recent findings confirmed 66\% aerobic and 34\% anaerobic contribution for the total 200-m event (Figueiredo et al. 2011). Aerobic fitness should be developed before more specific and high-intensity training such as aerobic power and lactate tolerance (Pyne et al. 2001). So, the middle of the season performance decline from $\mathrm{TP}_{1}$ to $\mathrm{TP}_{2}$ for Int swimmers can be related to a decrease in total volume of aerobic and anaerobic training, suggesting that periodization was ineffective in developing the various aspects of both energetic pathways. However, the training load was not harmful for both cohorts. In the national level group, five swimmers were presenting better performances at all time periods. Only one swimmer did not demonstrate the same trend. Since a reduced sample size the performance median values are more informative than mean ones. In this sense, some given swimmer with a large variation regarding the mean data lead to the rejection of the null hypothesis. Thus, some caution should exist when interpreting some inferential data as for this case. Despite a relative change (values from $\mathrm{TP}_{2}$ to $\mathrm{TP}_{3}$ showed a decline, $0.19 \pm 3.87 \%$ ) from a qualitative point of view, most national level swimmers demonstrated better 
Table 2 Interperiod Spearman correlation coefficients of performance, energetic and biomechanical variables measured in elite swimmers $(n=10)$ at the time periods of training

\begin{tabular}{llll}
\hline Variable & $\mathrm{TP}_{1}$ vs. $\mathrm{TP}_{2}$ & $\mathrm{TP}_{2}$ vs. $\mathrm{TP}_{3}$ & $\mathrm{TP}_{1}$ vs. $\mathrm{TP}_{3}$ \\
\hline $200 \mathrm{~m} \mathrm{(s)}$ & $0.88^{* *}$ & $0.56^{* *}$ & $0.64 *$ \\
$V 4\left(\mathrm{~m} \mathrm{~s}^{-1}\right)$ & $0.82^{* *}$ & 0.33 & 0.42 \\
$\mathrm{SI} @ V 4\left(\mathrm{~m}^{2} \mathrm{c}^{-1} \mathrm{~s}^{-1}\right)$ & $0.95^{* *}$ & $0.83^{* *}$ & $0.77 * *$ \\
$\eta_{\mathrm{p}} @ V 4(\%)$ & $0.93^{* *}$ & $0.86^{* *}$ & $0.76^{*}$ \\
$\mathrm{SF} @ V 4(\mathrm{~Hz})$ & $0.90^{* *}$ & $0.65^{*}$ & $0.66^{*}$ \\
$\mathrm{SL} @ V 4(\mathrm{~m})$ & $0.92^{* *}$ & $0.72 *$ & $0.65^{*}$ \\
\hline
\end{tabular}

$* P<0.05$

** $P<0.01$

performances. It appears that Nat swimmers are not affected in a similar way as Int ones. Despite the aerobic and anaerobic load reduction, the continuous training provides sufficient stimulus for a slight performance variation across the season in the Nat cohort.

The inter-group comparison pointed out a significant and higher Int performance for all time periods $\left(\mathrm{TP}_{1}\right.$ $P=0.03 ; \mathrm{TP}_{2} P=0.03 ;$ and $\left.\mathrm{TP}_{3} P=0.02\right)$. Having increased energetic and biomechanical profiles, it is obvious that Int performances tend to be higher. At the same time, those Int need to perform at high-level on a regular basis not to be sent out from the financial and training, control and evaluation of National Olympic project.

\section{Energetics}

Changes with no significant meaning were observed in V4 as well. Because the energetic capacity of elite swimmers is characterized by extreme values at the upper limits, tracking energetic variables in this population presents an extra-challenge (Davison et al. 2009). Despite the absence of statistical significance, these findings confirm earlier observations about variations in $V 4$ after several months of aerobic training (Sharp et al. 1984; Wakayoshi et al. 1993; Pyne et al. 2001). The training induces muscle adaptations and improves the ability to produce energy aerobically (Madsen 1983). In $\mathrm{TP}_{3}$ a slight decline in Int swimmer's V4 was observed. This can be explained by extreme aerobic fitness values reached in the middle of the season. Probably Int swimmers have already reached their personal aerobic peak at this point. In addition, the decrease in the total training volume at an intensity of their aerobic capacity in $\mathrm{TP}_{3}$ may have contributed to this $V 4$ declining. So, the performance variation in the final stage of the season seems to be mainly due to an improvement in the anaerobic fitness and technical factors. On the other hand, Nat swimmers were able to increase $V 4$ at all time. As previously suggested, the aerobic training reduction throughout the season was not harmful for this cohort and the continuous training provided sufficient stimulus to increase aerobic capacity.

Int swimmers presented higher values of $V 4$ when compared to the Nat. Indeed, in the $\mathrm{TP}_{2}$ significant differences were observed between both groups $(P=0.05)$. V4 represents a unique combination of SF@V4 and SL@V4 (Craig and Pendergast 1979). Having higher SF and lower SL, less skilled swimmers experience more difficulties in sustaining a maximal aerobic effort (Fernandes et al. 2006). That is the reason why elite swimmers have a better capacity to maximize their energy input than lower level ones (Fernandes et al. 2006).

SI@V4 and $\eta_{\mathrm{p}} @ V 4$ are overall indicators of swimming efficiency. Both variables presented slight changes over the course of the study. SI@V4 has double effect from V4 (Costill et al. 1985). Slight and even non-meaningful changes in V4 and SL@V4 led to significant changes in SI@V4. Indeed, significant meaning $(P=0.05)$ was observed for the Nat SI@V4 from the $\mathrm{TP}_{2}$ to $\mathrm{TP}_{3}$. The higher time spent in low aerobic tasks related to technical training in the final stage of the season may explain this improvement in SI@V4 and $\eta_{\mathrm{p}} @ V 4$, resulting in a performance enhancement in both groups. It appears that the high aerobic capacity reached earlier in the season, along with the time spent on practicing technical drills from $\mathrm{TP}_{2}$ to $\mathrm{TP}_{3}$ was determinant in increasing swimming efficiency. To the best of our knowledge, limited longitudinal data are available regarding the SI@V4 and $\eta_{\mathrm{p}} @ V 4$ status throughout an entire season or a shorter period of time. Earlier observations concerning those variables aimed to analyze young swimmers and did not compare groups of different competitive level (Latt et al. 2009a, b). However, several cross-sectional studies have already suggested that Int swimmers present higher $S I$ and $\eta_{\mathrm{p}}$ values than Nat ones (e.g. Toussaint 1990; Sánchez and Arellano 2002). Int swimmers are able to maintain higher $S I$ values indicating an improved energetic capacity to delay the appearance of increased local muscular fatigue (Fernandes et al. 2006). Similar trend was also found in this study for the entire season.

\section{Biomechanics}

The more time spent in technical tasks had a positive effect on the stroke mechanics in both groups. However, different combinations were observed for the SF and SL relationships. Int swimmers presented an increase in the SL@V4 and a decrease in the SF@V4 across season with no significant meaning. At some point of their careers, elite swimmers obtain a maximal technical ability where it is difficult (but not impossible) to observe changes in stroke mechanics. Several papers reported that training imposed significant improvements in SL of top-level adult 
swimmers, leading to an increase in swimming velocity (Wakayoshi et al. 1993; Termin and Pendergast 2000). As the V4 increased, there was less choice of combining SF@V4 and SL@V4. So, the single possibility was to increase in a higher range the SL@V4 reducing the SF@V4. The SF@V4 reduction is in accordance with the strategy adopted by elite swimmers that made them more efficient than lower level ones.

On the other hand, technical training induced an increase in both SF@V4 and SL@V4 for Nat swimmers. It was previously suggested that an increase in SF associated with a maintenance in SL should not be considered as ineffective for the 200-m freestyle performance (HuotMarchand et al. 2005). So, the ability of Nat swimmers to use SF and SL relationship to progressively improve the energetic and biomechanical capacity is a major factor to enhance performance. Similar phenomenon was already observed in Division 1 male swimmers (Termin and Pendergast 2000).

When the inter-group comparison was carried out, the total improvement in SL@V4 was higher for the Int swimmers $(2.15 \pm 4.45 \%)$. Additionally, Int swimmers presented a higher SL@V4 and reduced SF@V4 than Nat ones at all time periods. Once again there is a lack of evidence about such topic in a longitudinal point of view, although it is consensual in cross-sectional design studies that high-level swimmers have an increased SL (Craig et al. 1985; Seifert et al. 2007). During the 100- and 400-m front crawl events faster swimmers tend to show a smaller decrease in SL than slower ones (Chollet et al. 1997; Laffite et al. 2004). Moreover, elite swimmers have the ability to maintain high SL values while increasing $v$ through $\mathrm{SF}$ increases during incremental exercises (Barbosa et al. 2008). This fact may be related to an increased capacity to deliver power output presented by the more skilled swimmers (Toussaint and Beck 1992). The literature also suggests that anthropometric characteristics (Zamparo et al. 1996), higher skill level (Barbosa et al. 2008) or genetic background (Costa et al. 2009) are determinant in the swimmers competitive level, and may facilitate skill acquisition related to specific tasks.

\section{Normative stability}

This data analysis procedure is related to the possibility of a swimmer to demonstrate a "stable" profile in his characteristics when compared to other swimmers (if he remains on his specific track of competitive level across the season, or if he tends to jump to another). It reports the term "stability" based on inter-individual instead of an intra-individual point of view. Low $K$ values were observed for V4 and SL@V4 throughout the competitive season suggesting that swimmers were able to change their competitive level related to those variables. On the other hand, for the SI@V4 high $K$ values were demonstrated. Despite the SI@V4 improvement observed for the Nat cohort, Int swimmers were able to increase their SI@V4 as well. So, for the Nat group, this slight change was not enough to change from a track of competitive level. Taking into account that SI@V4 values are near the statistical significance in $\mathrm{TP}_{1}$ and $\mathrm{TP}_{3}$ when comparing both groups, the SI@V4 can be used as an indicator of performance variation across the competitive season.

The tracking based on auto-correlation coefficients were high for most variables analyzed, except for the $V 4$ $(0.33 \leq r \leq 0.82) \quad$ where a low-high stability was observed. This suggests that during a single season the margin of improvement for adult elite swimmers energetic and biomechanical profiles is too small. Indeed, their ability to reach a higher competitive level throughout a single season remains scarce. For two consecutive seasons high values of correlation coefficients were verified for anthropometric, body composition, biomechanical and energetic variables in young swimmers (Latt et al. 2009a, b). Nevertheless, when increasing the time frame analysis, the stability might decrease (Costa et al. 2010a). A couple of papers presented a moderate (Costa et al. 2010a) and low (Costa et al. 2010b) stability for elite swimmers competitive performance in a 5 and 7 years' time frame, respectively. The low-high range in V4 stability can be related to several episodes that might play a major role such as: (1) an acute or a chronic injury (Wolf et al. 2009); (2) illness (Hellard et al. 2010); (3) overtraining (Pelayo et al. 1996) or; (4) preference to improve academic success instead of sports performance.

The small sample of subjects does not allow strong statements about the differences between Nat and Int swimmers. If one takes another small sample of subjects from some other Country then the present findings may (or may not) repeat. However, it was demonstrated that some practical parameters were stable enough to be used as diagnostic tools to observe changes in both biomechanical and energetic profiles along with enhancement of overall swimming performance. Although most of the times this kind of research are done with convenience samples, if possible, in future the use of larger number of subjects should be considered to avoid the power sample issue.

\section{Conclusions}

Despite slight changes, elite swimmers performance, energetic and biomechanical profiles remain unaltered throughout the competitive season. Int swimmers are able to maintain a higher energetic and biomechanical capacity than Nat ones at all time. Later in the season, those slight 
changes in the 200-m freestyle performance are achieved due to an increase in anaerobic tasks and technical training. In addition, the SI@V4 can be used as an indicator of performance variation throughout the competitive season.

Acknowledgments The authors wish to thanks the support of all swimmers and coaches. Mário J Costa acknowledges the Portuguese Science and Technology Foundation (FCT) for the PhD grant (SFRH/ $\mathrm{BD} / 62005 / 2009)$.

Ethical standards The Institutional Review Board of the Polytechnic Institute of Bragança approved the study design. All subjects gave their informed consent prior to their inclusion in the study. The procedures were in accordance to the Declaration of Helsinki in respect to Human research.

Conflict of interest The authors declare that they have no conflict of interest.

\section{References}

Anderson M, Hopkins W, Roberts A, Pyne D (2008) Ability of test measures to predict competitive performance in elite swimmers. J Sports Sci 26:123-130

Barbosa TM, Fernandes RJ, Keskinen KL, Vilas-Boas JP (2008) The influence of stroke mechanics into energy cost of elite swimmers. Eur J Appl Physiol 103:139-149

Chollet D, Pelayo P, Delaplace C, Tourny C, Sidney M (1997) Stroking characteristic variations in the 100-m freestyle for male swimmers of differing skill. Percept Mot Skills 85:167-177

Costa AM, Silva AJ, Garrido ND, Louro H, Marinho DA, Marques MC, Breitenfeld L (2009) Angiotensin converting enzyme genotype affects skeletal muscle strength in elite athletes. J Sport Sci Med 8:410-418

Costa MJ, Marinho DA, Reis VM, Silva AJ, Marques MC, Bragada JA, Barbosa TM (2010a) Tracking the performance of worldranked swimmers. J Sports Sci Med 9:411-417

Costa MJ, Marinho DA, Reis VM, Silva AJ, Marques MC, Bragada JA, Barbosa TM (2010b) Stability and prediction of 100-m breaststroke performance during the elite swimmers careers. In: Kjendlie PL, Stallman RK and Cabri J (eds) XIth International Symposium on Biomechanics and Medicine in Swimming, Oslo, pp 272-273

Costill D, Kovaleski J, Porter D, Fielding R, King D (1985) Energy expenditure during front crawl swimming: predicting success in middle-distance events. Int J Sports Med 6:266-270

Costill DL, Thomas R, Robergs RA, Pascoe D, Lambert C, Barr S, Fink WJ (1991) Adaptations to swimming training: influence of training volume. Med Sci Sports Exerc 23:371-377

Craig A, Pendergast D (1979) Relationships of stroke rate, distance per stroke and velocity in competitive swimming. Med Sci Sports Exerc 11:278-283

Craig A, Skehan P, Pawelczyk J, Boomer W (1985) Velocity, stroke rate and distance per stroke during elite swimming competition. Med Sci Sports Exerc 17:625-634

Davison R, Someren K, Jones A (2009) Physiological monitoring of the Olympic athlete. J Sport Sci 27:1433-1442

Fernandes R, Billat V, Cruz A, Colaço P, Cardoso C, Vilas-Boas JP (2006) Does net energy of swimming affect time to exhaustion at the individual's maximal oxygen consumption velocity? J Sports Med Phys Fit 46:373-380
Figueiredo P, Zamparo P, Sousa A, Vilas-Boas JP, Fernandes RJ (2011) An energy balance of the $200 \mathrm{~m}$ front crawl race. Eur $\mathbf{J}$ Appl Physiol. doi:10.1007/s00421-010-1696-Z

Hay J, Guimarães A (1983) A quantitative look at swimming biomechanics. Swim Tech 20:11-17

Hellard P, Guimaraes F, Avalos M, Houel N, Hausswirth C, Toussaint JF (2010) Modeling the Association between Heart Rate Variability and Illness in Elite Swimmers. Med Sci Sports Exerc (in press)

Houston ME, Wilson DM, Green HJ, Thomson JA, Ranney DA (1981) Physiological and muscle enzyme adaptations to two different intensities of swim training. Eur J Appl Physiol Occup Physiol 46:283-291

Huot-Marchand F, Nesi X, Sidney M, Alberty M, Pelayo P (2005) Variatons of stroking parameters associated with 200-m competitive performance improvement in top-standard front crawl swimmers. Sports Biomech 4:89-99

Laffite LP, Vilas-Boas JP, Demarle A, Silva J, Fernandes R, Billat V (2004) Changes in physiological and stroke parameters during a maximal 400-m free swimming test in elite swimmers. Can J Appl Physiol 29(Suppl.):S17-S31

Landis J, Koch G (1977) The measurement of observer agreement for categorical data. Biometrics 33:159-174

Latt E, Jurimae J, Haljaste K, Cicchella A, Purge P, Jurimae T (2009a) Physical development and swimming performance during biological maturation in young female swimmers. Coll Antropol 33:117-122

Latt E, Jurimae J, Haljaste K (2009b) Longitudinal development of physical and performance parameters during biological maturation of young male swimmers. Percept Mot Skills 108:297-307

Madsen O (1983) Aerobic training: not so fast there. Swimming Tech 20:13-17

Magel JR, Foglia GF, McArdle WD, Gutin B, Pechar GS, Katch FI (1975) Specificity of swim training on maximum oxygen uptake. J Appl Physiol 38:151-155

Malina RM (2001) Adherence to physical activity from childhood to adulthood: a perspective forma tracking studies. Quest 53:346-355

Mingheli F, Castro F (2006) Kinematics parameters of crawl stroke sprinting through a training season. In: Vilas-Boas JP, Alves F, Marques A (eds) Biomechanics and Medicine in Swimming X, Port J Sport Sci, Porto, pp 102-103

Mujika I, Chatard JC, Busso T, Geyssant A, Barale F, Lacoste L (1995) Effects of training on performance in competitive swimming. Can J Appl Physiol 20:395-406

Mujika I, Padilla S, Pyne D (2002) Swimming performance changes during the final 3 weeks of training leading to the Sydney 2000 Olympic Games. Int J Sports Med 23:582-587

Pelayo P, Mujika I, Sidney M, Chatard JC (1996) Blood lactate recovery measurements, training, and performance during a 23-week period of competitive swimming. Eur J Appl Physiol Occup Physiol 74:107-113

Pendergast DR, Capelli C, Craig AB, di Pramperi PE, Minetti AE, Mollendorf J, Termin II, Zamparo P (2006) Biophysics in swimming. In: Vilas-Boas JP, Alves F, Marques A (eds) Biomechanics and medicine in swimming X, Porto, pp 185-189

Pyne DB, Lee H, Swanwick KM (2001) Monitoring the lactate threshold in world ranked swimmers. Med Sci Sports Exerc 33:291-297

Reis J, Alves F (2006) Training induced changes in critical velocity and V4 in age group swimmers. In: Vilas-Boas JP, Alves F, Marques A (eds) Biomechanics and Medicine in Swimming X. Port J Sport Sci, Porto, pp 55-56

Robertson EY, Aughey RJ, Anson JM, Hopkins WG, Pyne DB (2010) Effects of simulated and real altitude exposure in elite swimmers. J Strength Cond Res 24:487-493 
Sánchez J, Arellano R (2002) Stroke index values according to level, gender, swimming style and event race distance. In: Gianikellis $\mathrm{K}$ (ed) XXth International Symposium on Biomechanics in Sports, Cáceres pp 56-59

Seifert L, Chollet D, Chatard JC (2007) Kinematic change during a 100-m front crawl: effects of performance level and gender. Med Sci Sports Exerc 39:1784-1793

Sharp R, Vitelli C, Costill D, Thomas R (1984) Comparison between blood lactate and heart rate profiles during a season of competitive swim training. J Swim Res 1:17-20

Termin B, Pendergast D (2000) Training using the stroke-frequency velocity relationship to combine biomechanical and metabolic paradigms. J Swim Res 14:9-17

Toussaint H (1990) Differences in propelling efficiency between competitive and triathlon swimmers. Med Sci Sports Exerc 22:409-415

Toussaint H, Beck C (1992) Biomechanics of competitive front crawl swimming. Sports Med 13:8-24

Trinity J, Pahnke M, Sterkel J, Coyle E (2008) Maximal power and performance during a swim taper. Int J Sports Med 29:500-506
Troup J (1991) Aerobic characteristics of the four competitive strokes. In: Troup J (ed) International Center for Aquatic Research Annual, Studies by the International Center for Aquatic Research. US Swimming Press, Colorado Spring, pp 3-7

Wakayoshi K, Yoshida T, Ikuta Y, Mutoh Y, Miyashita M (1993) Adaptations to six months of aerobic swim training: changes in velocity, stroke rate, stroke length and blood lactate. Int J Sports Med 14:368-372

Wolf BR, Ebinger AE, Lawler MP, Britton CL (2009) Injury patterns in Division I collegiate swimming. Am J Sports Med 37:2037-2042

Zamparo P (2006) Effects of age and gender on the propelling efficiency of the arm stroke. Eur J Appl Physiol 97:52-58

Zamparo P, Antonutto G, Capelli C, Francescato M, Girardis M, Sangoi R, Soule R, Pendergast D (1996) Effects of body size, body density, gender and growth on underwater torque. Scand $\mathrm{J}$ Med Sci Sports 6:273-280

Zamparo P, Pendergast D, Mollendorf J, Termin A, Minetti A (2005) An energy balance of front crawl. Eur J Appl Physiol 94:134-144 